\title{
PRODUCTION METHODS FOR METALLIC FOAMS
}

\author{
J. BANHART, J. BAUMEISTER \\ Fraunhofer-Institute for Applied Materials Research (IFAM), Lesumer Heerstraße 36, \\ 28717 Bremen, Germany, ban@ifam.fhg.de
}

\begin{abstract}
The possibilities for making metallic foams or similar porous metal structures are reviewed. The various processes are classified according to the state of the starting metal - liquid, powdered, ionised. Liquid metal can be foamed directly by injecting gas, gas-releasing foaming agents or by producing supersaturated metal-gas solutions. Indirect methods include investment casting and usage of filler materials. Metal powders can also be used as starting materials for metallic foams: mixtures of such powders with foaming agents are compacted to foamable precursor materials that can be foamed in a second step. Instead of foaming agents inert gas can be directly entrapped in the precursor. Metal foams can also be made from metal powder slurries or by using polymer/powder mixtures. Finally, galvanic electro-deposition also allows to make highly porous metallic structures with open pores.
\end{abstract}

\section{INTRODUCTION}

Cellular materials are widespread in everyday life and are used for cushioning, insulating, damping, constructing, filtering purposes and many other applications. Highly porous materials are known to have a high stiffness combined with a very low specific weight. For this reason cellular materials frequently occur in nature as constructional materials (e.g. woods and bones). The fact that even metals and metallic alloys can be produced as cellular solids or metal foams is not as well known as the possibility to foam more traditional engineering materials such as polymers, ceramics or glass. Metallic foams offer interesting perspectives due to the combination of properties which are related to the metallic character on the one and to the porous structure on the other hand.

In the past 40 years many attempts have been undertaken to foam metals or to produce porous metallic structures. In the present review some of the more important and successful procedures are described.

There is no clear-cut and generally accepted definition for the term "foam". First of all, one has to distinguish between liquid and solid foams. A liquid foam is a fine dispersion of gas bubbles in a liquid. Cooling down a liquid foam beneath the melting point of the respective material yields a frozen liquid foam which is then clearly a solid foam. What is generally meant in the context of metallic foams are in general solid metallic foams. One could restrict usage of the word "solid foam" to materials which originally were in the liquid state. However, customarily other porous structures such as sintered metal powders are often also called "foams" although they never were in a liquid state. So one often extends the usage of the word "foam" to porous metal structures which are not 
actually foams, but resemble foams regarding their high porosity, the inter-connectivity of the solid material and their irregular structure.

\section{FOAMS MADE FROM METALLIC MELTS}

A first group of foam making processes starts from the molten metal that is processed to a porous material by either foaming it directly, by using an indirect method via a polymer foam or by casting the liquid metal around solid filler materials which reserve space for the pores or which remain in the foam.

\section{Direct foaming of melts}

Metallic melts can be foamed directly under certain circumstances by injecting gases into the liquid. Normally, the gas bubbles which are then formed in the metallic melt will tend to rise to its surface quickly due to the high buoyancy forces in the high-density liquid but this rise can be impeded by increasing the viscosity of the molten metal. This can be done by adding fine ceramic powders or alloying elements which form particles in the melt.

It should be noted that numerous attempts to foam liquid metals have been undertaken in the 60s and 70s (see e.g. Ref. 1), but apparently the processes then invented could not be sufficiently optimised to yield foams of a satisfactory quality and cost. In the past ten years, however, a number of new developments have taken place so that nowadays better production routes are available.

Melting the Al matrix metal

I

Addition of reinforcing particles to melt $\left(5-20 \% \mathrm{SiC}\right.$ or $\left.\mathrm{Al}_{2} \mathrm{O}_{3}\right)$

$\sqrt{3}$

Injection of gas into the melt using a rotating impeller

I

Pulling off the floating foam from the surface of the melt (continuously, sheet material)

$\sqrt{3}$

Influencing the pore structure by gas pressure, impeller rotation speed and other parameters

\section{Fig. 1: Direct foaming of melts (MMC foams)}

Currently there are two ways for directly foaming metallic melts. One line is being exploited by Cymat (originally by Alcan) in Canada and Hydro Aluminium in Norway ${ }^{2-5}$ for foaming aluminium and aluminium alloys. According to this process that is depicted in schematical form in Fig. 1, silicon carbide, aluminium oxide or magnesium oxide particles are used to enhance the viscosity of the melt. Therefore, the first step consists of making an aluminium melt containing one of these substances. The problem to be solved resembles the one encountered in making ordinary MMCs, namely the problem of wetting the particles by the melt and of achieving a homogeneous distribution of the reinforcing particles ${ }^{6}$.

The liquid MMC melt is foamed in a second step by blowing gases (air, nitrogen, argon) into it using specially designed rotating impellers. These impellers have to produce very fine gas bubbles in the melt and distribute them homogeneously. The foam that is generated this way floats up to the surface of the liquid where it can be pulled off e.g. by 
means of a conveyor band. Care has to be taken not to damage the foam structure by shearing the semi-solid foam too much. The resulting material is in principle as long as desired, as wide as the vessel containing the liquid metal allows it and typically $10 \mathrm{~cm}$ thick. The foamed material is either used in the state it comes out of the casting machine having a closed outer surface or is cut into the required shape after foaming. Due to the high content of ceramic particles, machining of the MMC-foams might be a problem. The advantage of the process is the ability of producing large volumes at a rather low cost and the low density that can be achieved. Porosities range from 80 to $97 \%$. A possible disadvantage is the eventual necessity for cutting the foam and therefore opening the cells and the brittleness of the MMC foam due to the reinforcing particles contained in the cell walls. However, attempts for making shaped parts by casting the semi-liquid foam into moulds or by shaping the emerging foam with rolls have been undertaken $^{7,8}$ thus removing one of these disadvantages. Some properties of such metal foams have been investigated and are given in the literature ${ }^{9,10}$. MMC foams are probably the least expensive ones compared to other metallic foams.

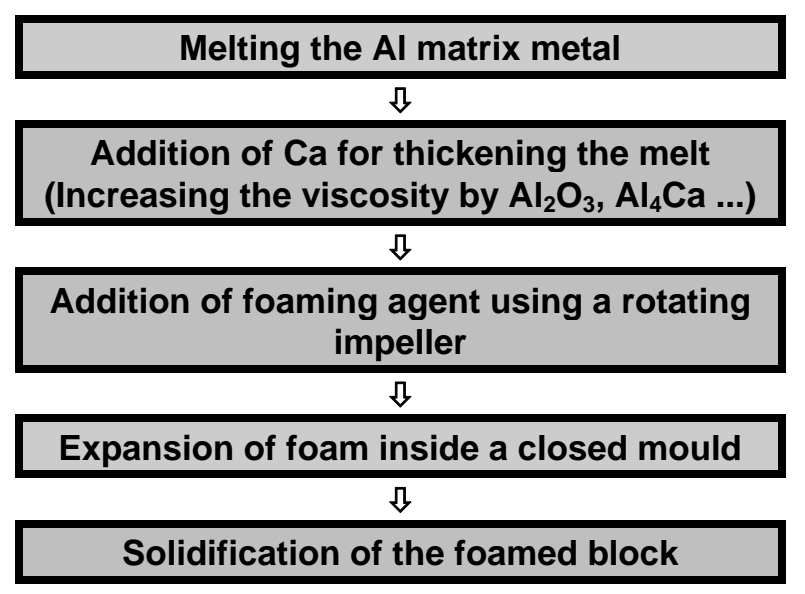

Fig. 2: Direct foaming of melts (ALPORASProcess)
The second way for foaming melts directly is to add a foaming agent to the melt instead of blowing gas into it ${ }^{11,12}$. The foaming agent decomposes under the influence of heat and releases gas which then propels the foaming process. For the process that is currently in a state of a small-scale commercial exploitation at Shinko Wire in Japan, calcium is used to stabilise the melt (probably forming an $\mathrm{Al}_{4} \mathrm{Ca}$ intermetallic) and titanium hydride $\mathrm{TiH}_{2}$ serves as the foaming agent releasing hydrogen gas when it is heated. The foamed aluminium is produced in batches of approximately $2000 \times 1000 \times 600 \mathrm{~mm}$. Typical densities are 0.25 to $0.33 \mathrm{~g} / \mathrm{cm}^{3}$. The blocks are cut into

sheets of the required thickness ${ }^{13}$, e.g. $5 \mathrm{~mm}$ to $250 \mathrm{~mm}$, standard thickness $10 \mathrm{~mm}$. The pore structure of the material - named ALPORAS - is rather uniform ${ }^{14}$. Mechanical ${ }^{14}$ and sound absorption properties ${ }^{15}$ have been measured. The material has been reported to be more expensive than the MMC foams described above.

\section{Solid-gas eutectic solidification (Gasars)}

A method that was developed some years ago in the Ukraine ${ }^{16}$ exploits the fact that some liquid metals form a eutectic system with hydrogen gas. By solving hydrogen in these metals under high pressure (typically 50 atms) one first prepares a melt that is pore free with the hydrogen completely solved in the metal (see Fig. 3). If one then reduces temperature and pressure, one forces the melt to go through the two-phase regions. Beneath the eutectic temperature one arrives at a two-phase field corresponding to a solid plus the gas. If the process parameters - cooling rate and pressure profile - are chosen appropriately, the gas will accumulate in fine gas bubbles in the solid, thus forming a foam. The possibility of solidifying the liquid directionally offers the advantage of making foams with elongated pores. If the casting vessel is cylindrical, 


\begin{tabular}{|c|}
\hline Melting the metal in an autoclave \\
\hline$\sqrt{2}$ \\
\hline $\begin{array}{c}\text { Solving hydrogen gas in the melt under } \\
\text { high pressure } \\
\text { (Solubility depends on pressure, alloy } \\
\text { composition etc.) }\end{array}$ \\
\hline$\sqrt{ }$ \\
\hline $\begin{array}{c}\text { Casting the saturated melt into a mould } \\
\text { within the autoclave }\end{array}$ \\
\hline$\sqrt{2}$ \\
\hline $\begin{array}{l}\text { Directional solidification of the melt under } \\
\text { reduced hydrogen pressure } \\
\text { (Precipitation of } \mathrm{H}_{2} \text { gas at the solidification } \\
\text { front) }\end{array}$ \\
\hline$\sqrt{2}$ \\
\hline $\begin{array}{l}\text { Influencing the pore structure by gas } \\
\text { pressure and the direction of solidification }\end{array}$ \\
\hline
\end{tabular}

Fig. 3: Foaming metals by the Gasar process

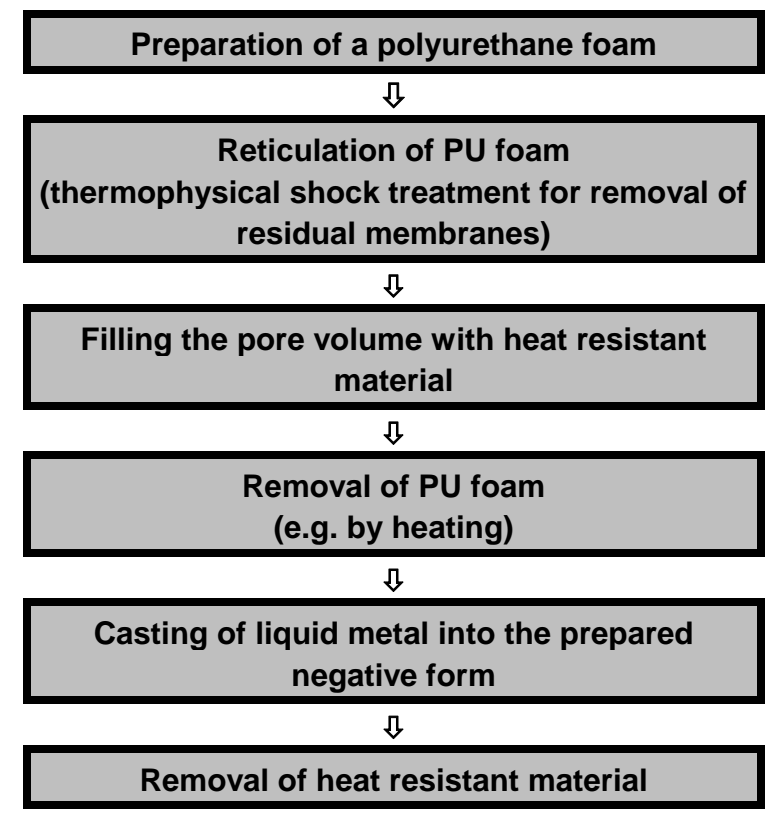

Fig. 4: Making metallic foams by investment casting

radial and axial pores can be made ${ }^{17}$. The maximum porosities that can be achieved by this process are not very high (5-75\%) but metals with medium and high melting points such as copper and nickel can be foamed. The pore structure of such foams - called gasars - is somewhat problematic ${ }^{18,19}$, so that further improvements have to be awaited. The mechanical properties (compression and tension) of gasars have been characterised recently ${ }^{20,21}$.

\section{$\underline{\text { Investment casting }}$}

Metal foams can also be fabricated without directly foaming the metal ${ }^{22-24}$. For this a polymer foam is used as a starting point (Fig. 4). The polymer foam is turned into a structure with open pores by manipulating the foaming process or by a reticulation treatment. The foam is then filled with a slurry of heat resistant material, e.g. a mixture of mullite, phenolic resin and calcium carbonate ${ }^{23}$. After drying the polymer is removed and molten metal is cast into the resulting open voids which exactly represent the original foam structure. After removal of the mould material (e.g. by pressurised water) a metallic foam is obtained that is an exact image of the original polymer foam. Fig. 5 shows a micrograph of such a foam that is being sold by ERG in California under the trade name DUOCEL. Various grades are available ranging from 2.5 to 16 pores per cm (10 to $40 \mathrm{ppi}$ ). Complex shaped parts can be fabricated by pre-forming the polymer foam. Prices have been reported to

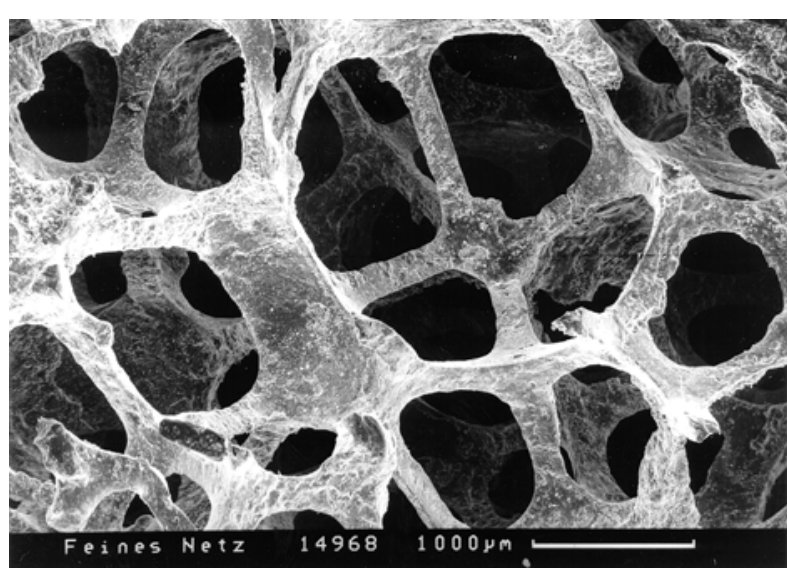

Fig. 5: SEM image of a metal foam made by investment casting (DUOCEL) 
be high. Aluminium alloys are usually used but other metals can also be processed. The densities and foam morphologies are of course determined by the polymer foam. Porosities typically range from 80 to $97 \%$.

\section{Syntactic foams using filler materials}

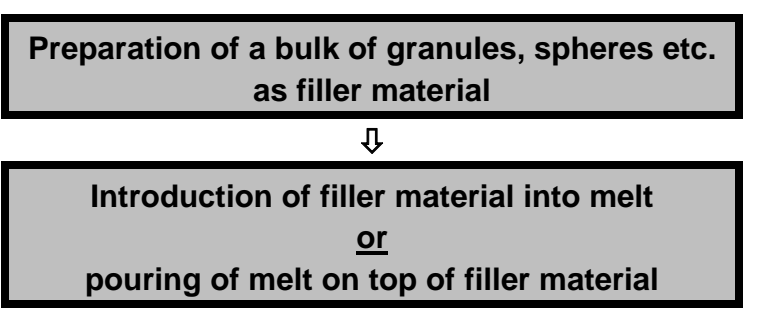

ת

Solidification of melt

n

optionally: removal of filler material (e.g. by heating)

Fig. 6: Making metallic foams using filler materials

Light-weight porous metals can be produced by casting around inorganic granules or hollow spheres of low density or by infiltrating such materials with a liquid melt (Fig. 6). A loose bulk of expanded clay granules, foamed glass spheres of aluminium oxide hollow spheres can be used for this ${ }^{25}$. The granules are then introduced into the melt or the melt is poured over the bulk of filler material. The heat capacity and conductivity of the granules is very low and therefore does not disturb the flow of the metal too much. Due to the high surface tension of the liquid metal wetting of the granules is a problem and in general the interstices between the granules will not be filled completely. Creating a slight vacuum or an external pressure facilitates infiltration significantly. A wide range of metals can be processed this way including aluminium, magnesium, zinc, lead, tin etc. Parts of a predefined shape can be fabricated by designing a mould of the appropriate geometry. Sandwich panels have also been made ${ }^{26}$.

\section{FOAMS MADE FROM METAL POWDERS}

Instead of the molten metal, metal powders can be used to make porous metallic structures. Again, there are several different methods which can be applied. In some of these processes the powders are processed into a compact precursor material prior to the actual foaming step, in others powders (or fibres, hollow spheres etc. which are considered to be powders here) are used for direct processing.

\section{Fraunhofer Process}

Foamed metals can be produced by a powder metallurgical method invented and patented $^{27-29}$ at Fraunhofer-Institute in Bremen, Germany .

The production process begins with the mixing of metal powders - elementary metals, alloys or powder blends - with a foaming agent, after which the mix is compacted to yield a dense, semi-finished product (Fig. 7). In principle, the compaction can be done by any technique that ensures that the foaming agent is embedded into the metal matrix without any residual open porosity.

Mat. Res. Soc. Symp. Proc. Vol. 521, ${ }^{\odot} 1998$ Materials Research Society 
Mixing powders with a foaming agent

Compaction of powder blend into a dense (foamable) precursor material

\

Optionally: working of precursor material by standard deformation techniques

Foaming of precursor material by heating it to its melting temperature

Fig. 7: Powder metallurgical process for making foamed metals

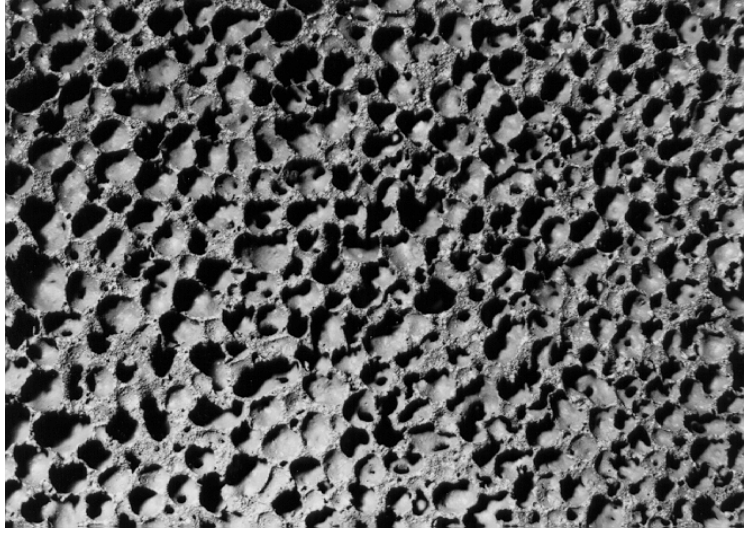

Fig. 8: Lead foam made from metal powder (scale approx. 1:4)

Examples for such compaction methods are uniaxial compression, extrusion or powder rolling ${ }^{26}$. Which compaction method is chosen depends on the required shape of the precursor material. However, extrusion seems to be the most economical method at the moment and is therefore the preferred method. Rectangular profiles with various cross sections are usually made. Thins sheets are then obtained by rolling.

Heat treatment at temperatures near the melting point of the matrix material is the next step. During this process the foaming agent, which is homogeneously distributed within the dense metallic matrix, decomposes. The released gas forces the compacted P/M material to expand thus forming its highly porous structure. Prior to foaming the precursor material can be processed into sheets, rods, profiles and other shapes etc. by conventional techniques like rolling, swaging or extrusion in order to improve the flow conditions during foaming inside moulds. The density of metal foams can be controlled by adjusting the content of foaming agent and several other foaming parameters such as temperatures and heating rates. If metal hydrides are used as foaming agents, a content of less than $1 \%$ is sufficient in most cases.

Although most application ideas are based on aluminium foams, the Fraunhofer method is not restricted to this metal: tin, zinc, brass, lead, and some other metals and alloys can also be foamed by choosing appropriate foaming agents and process parameters. The most common alloys for foaming, however, are pure aluminium, $2 X X X$ alloys and $6 \mathrm{XXX}$ alloys. Casting alloys, such as AISi7 and AISi12, are also frequently used because of their low melting point and good foaming properties, while in principle virtually any aluminium alloy can be foamed by properly adjusting the process parameters. Fig. 8 shows a typical cross section of a P/M foam. One sees that the distribution of cell sizes and shapes is random which is typical for a foaming process.

Foaming a piece of precursor material in a furnace results in a lump of metal foam with an undefined shape unless the expansion is limited in certain directions. This is done by inserting the precursor material into a hollow mould and expanding it by heating. In this way near-net shaped parts can be prepared. Quite complicated parts can be manufactured by injecting the expanding foam into suitable moulds and allowing for final expansion there ${ }^{30}$. 


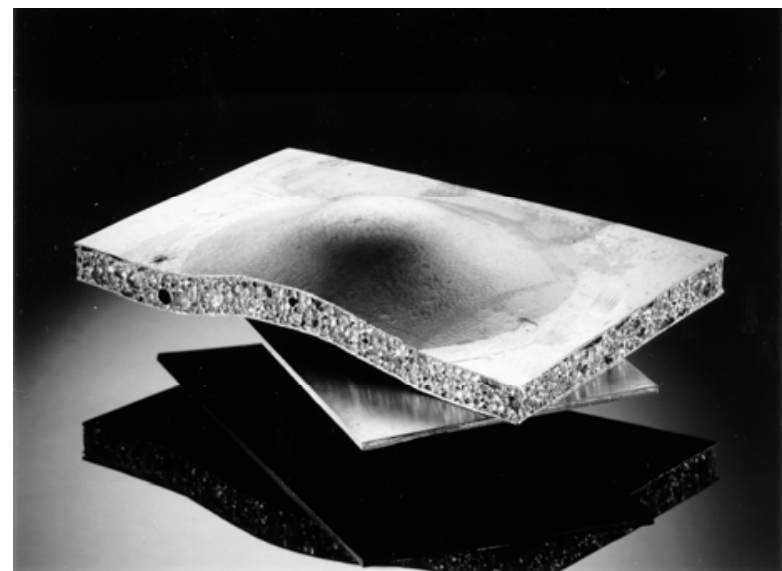

Fig. 9: Composite structure made of an aluminium foam core and steel face sheets (size $250 \times 250 \times 10 \mathrm{~mm}^{3}$ )

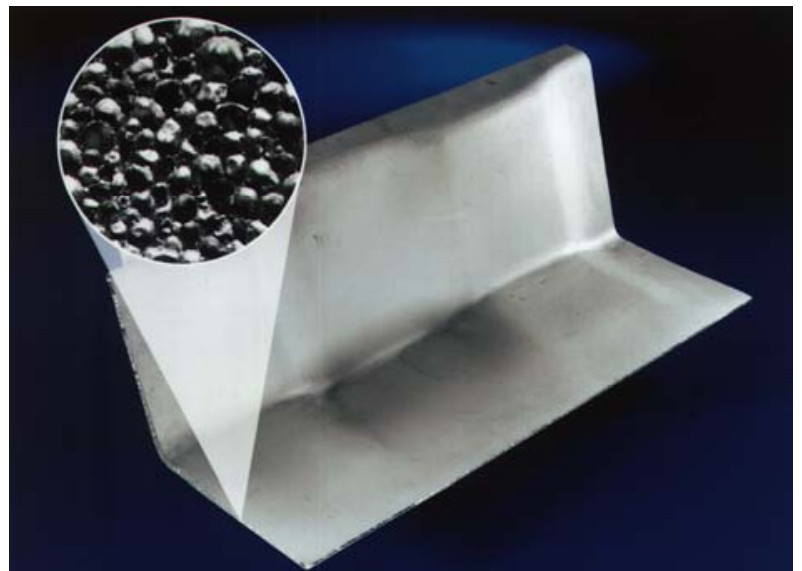

Fig. 10: 3d-shaped sandwich of an aluminium foam with aluminium face sheets (width 1000mm, thickness $8 \mathrm{~mm}$ )

Sandwich panels consisting of a foamed metal core and face sheets can be obtained by gluing the face sheets to a sheet of foam. Alternatively, if a pure metallic bonding is required, conventional sheets of metal - aluminium or steel - are roll-cladded to a sheet of foamable precursor material ${ }^{29}$. The resulting composite can be deformed in an optional step, e.g. by deep drawing. The final heat treatment then leads to sandwich structures such as the ones shown in Fig. 9 and 10. Aluminium foam can be combined with steel face sheets (Fig. 9) as well as with aluminium face sheets (Fig. 10). The large aluminium/aluminium foam part shown in Fig. 10 was a joint development of the German car maker Karmann and Fraunhofer-Institute for a concept car in which structural aluminium foam applications were demonstrated. The part is thought to replace the rear seat wall and has an enhanced stiffness at lower weight as compared to the conventional steel part.

Tubes can be filled with aluminium foam in various ways as shown in Fig. 11.

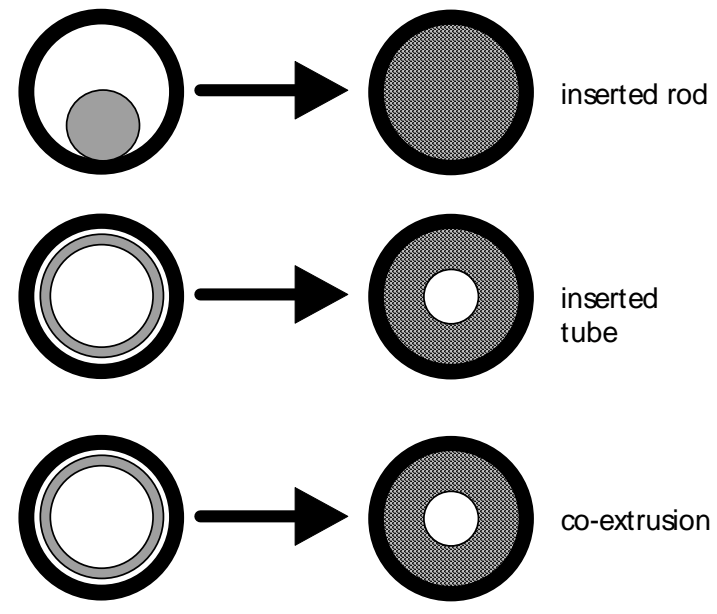

Fig. 11: Methods for filling tubes with metal foam $^{29}$

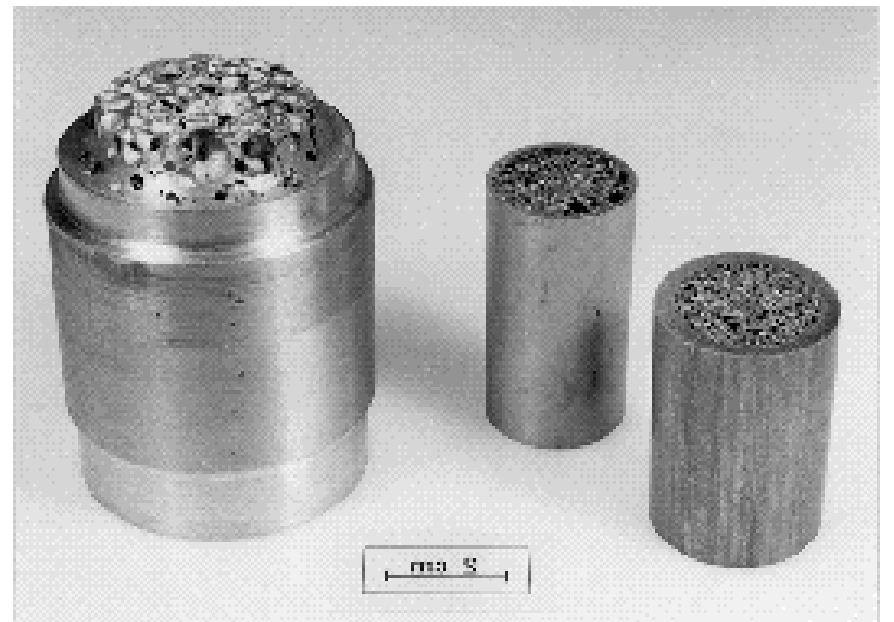

Figure 12: Foam filled aluminium tubes. Foam: AlSi12 alloy, tube: 6061 alloy 
The easiest way is to insert a rod of foamable precursor material into the tube to be filled and to place the tube into a furnace. The precursor material will start to foam and eventually fill the profile completely. The disadvantage of this method is, that only tubes with a significantly higher melting temperature as compared to the material to be foamed - e.g. steel tubes - can be used. If aluminium tubes are to be filled with foam the top of the tub will melt during foaming because it is not supported mechanically and the heat from the furnace can not be conducted into the precursor material. Thus a different way has to be chosen. One way is to insert a foamable tube into the tube to be filled. Then the foam will expand towards the centre of the tube. The foamable material is always in contact with the outer tube and therefore supports it. The expansion of the foam can be limited to a certain wall thickness by using a core in the centre of the tube. The third possibility is similar to the second but requires a co-extruded structure consisting of an outer tube of conventional aluminium and an inner tube of foamable precursor material. The two layers have a metallic bonding in contrast to the situation where the inner tube was merely inserted into the outer one. This bonding creates a better heat flow between the two tubes and therefore minimises the danger for the outer tube to be melted. Moreover, the metallic bonding between the foam and the outer tube will be better in this case as compared to the previous way, because between the inserted and the outer tube there are still oxide layers which partially prevent a metallic bonding even during foaming. Examples for foam-filled tubes are shown in Fig. 12.

More details of the Fraunhofer-process are given elsewhere ${ }^{31-33}$. Many mechanical and other physical properties have been characterised ${ }^{34-36}$. The process is now being extended to metals with higher melting points, e.g. iron and steel ${ }^{37-39}$. This extension of technology will introduce a wider scope of applications which make use of the high temperature resistance, extreme strength and other properties of these materials. Due to their excellent bio-compatibility, titanium foams could be used in prosthetical applications. However, these developments are just being worked out and are not yet in the advanced state-of-the-art of the aluminium foams.

\section{Gas Entrapment}

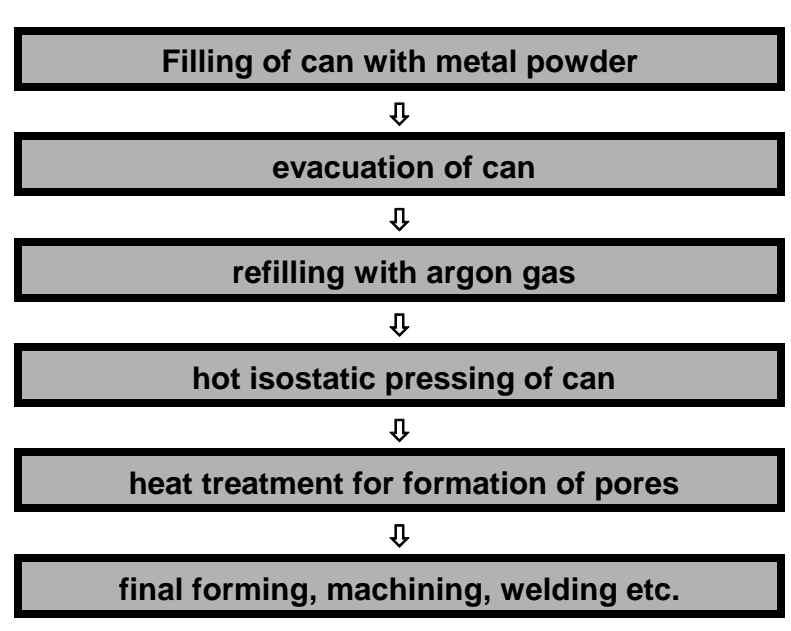

Fig. 13: Gas entrapment technique
Metals can be foamed without using a propelling agent by compressing powders to a precursor material and allowing gas to be entrapped in the metal structure during compaction $^{40,41}$ (see schematical representation in Fig. 13). Heating the precursor material then leads to an expansion of the metal due to the internal pressure created by the entrapped gas. The process has mainly been designed for making porous titanium structures. For this titanium powder is filled into a can that is then evacuated and refilled with argon gas. The filled can is densified by hot isostatic pressing, subsequently worked and finally foamed by means of an appropriate heat 


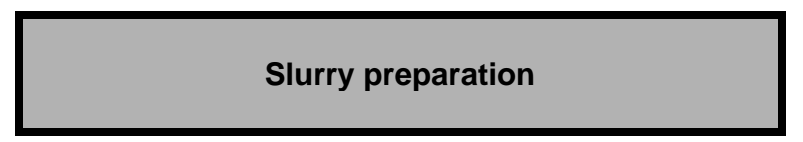

$\sqrt{n}$

Pouring of slurry into mould

$\sqrt{3}$

Foaming of slurry at elevated temperatures (depending on foaming agent)

$\sqrt{ }$

Drying of shaped part in mould

Fig. 14: Foaming of slurries
Preparation of polyurethane foam

』

Reticulation of PU foam

(thermophysical shock treatment for removal of residual membranes)

ת

Application of an electrical conductive coating (e.g. by PVD or by wetting with a graphite solution)

ป

Coating of PU foam by electro-deposition (not possible for $\mathrm{Al}$ or $\mathrm{Ti}$ )

ת

Removal of PU foam

(by decomposing or evaporating the PU material)

Fig. 15: Deposition technique for making metal foam

treatment. Refinements and extensions of this process have been developed and properties of materials and components have been characterised ${ }^{42,43}$.

\section{Foaming of Slurries}

Metallic foams can also be produced by preparing a slurry of metal powder mixed with a foaming agent (Fig. 14). The slurry is poured into a mould after mixing and dried there at elevated temperatures. The slurry becomes more viscous and starts to foam as gas begins to evolve. If sufficient stabilising measures have been taken the expanded slurry can be dried completely thus obtaining a metal foam. Such foams have been produced from aluminium powders using orthophosphoric acid with aluminium hydroxide or hydrochloric acid as a foaming agent ${ }^{44}$. Relative densities down to $7 \%$ have been achieved but there are problems with low strength ${ }^{45}$ and cracks in the foamed material.

\section{Other techniques}

There are many ways to make porous metallic products from metal powders, fibres or hollow spheres. The easiest way is to sinter loose powder fillings in a canister yielding a porous material with open porosity. Mixtures of metal powders and polymer binders can be extruded and then heat treated to produce porous parts ${ }^{46}$. This way porous materials with cylindrical pores can be produced. Reaction sintering of metal powder mixtures is also known to yield porous products.

Finally, hollow spheres made of titanium or steel, e.g., can be used to build highly porous structures by sintering ${ }^{47}$. Ordered and disordered arrangements can be realised. The density of such structures is extremely low with strengths that are still sufficient for many applications. By infiltrating the interstices between the hollow spheres the strength can be further increased. 


\section{DEPOSITION TECHNIQUES}

Deposition techniques start from the ionic state of metals (Fig. 15). The metal is galvanically deposited on a polymeric foam with open cells ${ }^{48-50}$. This process and the investment casting process therefore have in common that the actual foaming does not take place in the metallic state but with a polymer that is then replaced by a metal. Galvanic deposition on a polymer foam requires some electrical conductivity of the initial polymer foam. This is achieved by dipping the polymer foam into graphite solutions or by coating it with a thin conductive layer by metal vaporisation. After electroplating the polymer can be removed from the metal/polymer composite by thermal treatment. Foams of various grades can be fabricated ranging from 2 to 30 cells per $\mathrm{cm}$ (6 to 70 ppi). The preferred metal is nickel or a nickel-chrome alloy, but copper foams can also be fabricated.

Foams have been offered on a commercial basis under the name RETIMET (Dunlop Ltd., GB) and CELMET (Sumitomo, Japan, [46]). There is also a source in Belorussia ${ }^{50}$. Sheets with thicknesses between 2 and $10 \mathrm{~mm}$ are available with densities ranging from 0.2 to $0.5 \mathrm{~g} / \mathrm{cm}^{3}$.

\section{SUMMARY}

There is a large variety of methods to produce metallic foams or similar porous metal structures starting from liquid metal, powdered metal or from an electrolyte containing metal ions. Each process works for a selection of metals or alloys and yields foams of a typical morphology and density range. One therefore has the chance to tailor foam properties and to find a solution for one's specific application requirements.

The development of aluminium-based foams has been especially promoted by the request for certain structural light-weight applications so that the widest range of foams is available for this metal and its alloys. Various small-scale production facilities for aluminium foams are existent now in Japan, Canada, Slovakia, Austria and Germany. Some prototypes of aluminium foam parts have been developed and tested. However, it is not yet entirely clear in all cases whether the aluminium foam part can compete with the conventional part that it is supposed to replace both with respect to its physical and mechanical properties and to its economical performance.

The cost effectiveness of each process is different. It implies that only few methods are suitable for a high-volume mass production. Many of the methods will always be restricted to specialised applications where cost is not the most important parameter. Some of the processes for the production of aluminium foams - in particular the melt and the powder metallurgical processes - however, have the potential for mass production at reasonable costs. There seems to be a market for these materials provided that the unique properties of the metallic foam are fully exploited. This is the case when the foam has multiple functions, e.g. when its low weight in combination with its high-temperature resistance is desired. 


\section{REFERENCES}

[1] L.M. Niebylski, C.P. Jarema, P.A. Immethun, US Patent 3794481 (1974)

[2] I. Jin, L.D. Kenny, H. Sang, US Patent 4973358 (1990), PCT Patent WO 91/03578 (1991); PCT Patent WO 92/03582 (1992); US Patent 5112696 (1992)

[3] M. Thomas and L.D. Kenny, PCT Patent WO 94/172218 (1994)

[4] J.T. Wood, in: „Metal Foams“, Proc. Fraunhofer USA Metal Foam Symposium, 7.8.10.1997, Stanton, Delaware. Eds.: J. Banhart and H. Eifert, MIT Verlag/Publishing Bremen (1998), p. 31

[5] W. Ruch and B. Kirkevag, International Patent Application PCT/NO90/00115 (1990); WO 91/01387 (1991)

[6] D.J. Lloyd, A.D. McLeod, P.L. Morris, I. Jin, PCT Patent WO 91/19823 (1991)

[7] L.D. Kenny and M. Thomas, PCT Patent WO 94/09931 (1994)

[8] H. Sang, L.D. Kenny, I. Jin, PCT Patent WO 92/21457 (1992)

[9] O. Prakash, H. Sang, J.D. Embury, Mat. Sci. Eng. A199, 195 (1995)

[10] Product data sheets of Hydro Aluminium, Norway (1994)

[11] S. Akiyama et al., European Patent Application EP 0210803 A1 (1986), US Patent 4713277 (1987)

[12] M. Itoh and T. Miyoshi, this symposium, R3.2

[13] ALPORAS product information, Shinko Wire Co. Ltd., Japan (1998)

[14] M. Otsuka, A. Kojima, M. Itoh, E. Ishii, in „Science and Engineering of Light Metals“ Proc. Conf. RASELM '91, Tokyo, Oct. 1991, Ed.: Japan Institute of Light Metals, p. 999 (1991)

[15] E. Ishii, M. Itoh, Y. Morisawa, Kobe Steel Engineering Reports, 41, 59 (1991), (in Japanese)

[16] V.I. Shapovalov, US Patent 5181549 (1991); MRS-Bulletin, April 1994, p. 24-28; this symposium, R8.1

[17] Y. Zheng, S. Sridhar, K.C. Russell, in „Advances in Porous Materials“, eds: S. Komareni et al., MRS Society Bull. Vol. 371, p. 365, (1995)

[18] A. Pattnaik, S.C. Sanday, C.L. Vold, H.I. Aaronson, ibid., p. 371

[19] J.M. Wolla and V. Provenzano, ibid., p. 377

[20] V. Provenzano, J. Wolla, P. Matic, A. Geltmacher, A. Kee, ibid., p. 383

[21] A.E. Simone and L.J. Gibson, Acta Met. 44, 1437 (1996); J. Mat. Sci., 32, 451 (1997)

[22] DUOCELL product information, ERG Inc., Oakland Ca., USA (1996)

[23] Y. Yosida and C. Hayashi, Proc. Conf. Casting Science and Technology, Sept. 1990, p.103

[24] I. Wagner et al., DGM Hauptversammlung 20.-23.5.1997, Braunschweig, Germany, (abstract)

[25] W. Thiele, German Patent, 1933321 (1971); Metals and Materials, Aug. 1972, p. 349

[26] M. Hartmann, R.F. Singer, in „Metallschäume“, Proc. Symp. Metal Foams, 6.7.3.1997, Bremen, Germany. Ed.: J. Banhart, MIT-Verlag/Publishing Bremen (1997), p. 39, (in German); this symposium R5.5

[27] J. Baumeister, German Patent 4018360 (1990); US Patent 5151246 (1992); European Patent EP 0460392A1 (1996)

[28] J. Baumeister and H. Schrader, German Patent DE 4101630 (1991)

[29] J. Baumeister, J. Banhart, M. Weber, German Patent DE 4426627 (1997)

[30] F. Simancik, F. Schörghuber, this symposium, R3.7 
[31] J. Banhart and P. Weigand, Proc. cited in [4], p. 15

[32] J. Banhart, J. Baumeister, M. Weber, Proc. Euro. Conf. Advanced PM Materials (PM '95), Birmingham (UK), 23.-25. Oct. 1995, p. 201

[33] F. Simancík, J. Kovácik, F. Schörghuber, Proc. cited in [26], p. 171

[34] J. Banhart and J. Baumeister, J. Mat. Sci., in press, (1998)

[35] H.P. Degischer, U. Galovski, R. Gradinger, R. Kretz, F. Simancík, Proc. cited in [26], p. 79, (in German)

[36] C.J. Yu and J. Banhart, Proc. cited in [4], p.37

[37] B. Kriszt, A. Falahati, H.P. Degischer, Proc. cited in [26], p. 59, (in German)

[38] M. Weber, M. Knüwer , ibid., p. 73, (in German)

[39] C.J. Yu, H. Eifert, M. Knüwer, M. Weber, this symposium, R3.4

[40] R.L. Martin and R.J. Lederich, Metal Powder Report, Oct. 1992, p.30

[41] M.W. Kearns, P.A. Blenkinshop, A.C. Barber, T.W. Farthing, Int. J. Powder Met. 24, 59 (1988)

[42] D.S. Shih et al., this symposium R7.3

[43] this symposium, session R6

[44] J.P. Drolet, Int. J. Powder Met., 13, 223 (1977)

[45] S.B. Kulkarni and P. Ramakrishnan, Int. J. Powder Met. 9, 41 (1973)

[46] L. Tuchinskiy and R. Loutfy, Proc. cited in [4], p. 23

[47] K.M. Hurysz et al., this symposium, R5.3

[48] Product data sheet of SEAC B.V., Netherlands (1986)

[49] Product data sheet of Sumitomo Electric, Japan (1986)

[50] Product data sheet of Ecosot, Belorussia (1996) 